$20.5 \mathrm{~g}$. of recrystallized product was obtained,-a yield of $64 \%$. The solid melts at $200^{\circ}$. It is insoluble in most solvents.

Analysis. Calc. for $\mathrm{C}_{23} \mathrm{H}_{21} \mathrm{O}_{3} \mathrm{P}: \mathrm{P}, 8.24$. Found: 8.26.

Oxidation with ozone.-One $\mathrm{g}$. of the material was suspended in chloroform and treated with ozonized oxygen for the calculated length of time. The solvent was evaporated and the residue distilled with steam. $0.22 \mathrm{~g}$. of benzaldehyde was thus obtained, and $0.1 \mathrm{~g}$. of unoxidized material was found in the residue. The amount of benzaldehyde found is thus about $90 \%$ of the amount that could theoretically be obtained from the $0.9 \mathrm{~g}$. of material which was ozidized. In another experiment the residue left after evaporation of the solvent was treated with sodium carbonate solution and filtered from a small amount of oil. On acidification with nitric acid a dark flocculent precipitate was formed. It could not be obtained pure enough for analysis, but it was obviously an acid and contained phosphorus.

\title{
Summary.
}

1. Phosphorus trichloride: and phosphenyl chloride combine with dibenzal-acetone in glacial acetic acid to form unsaturated keto-phosphonic acids.

2. The unsaturated acids thus formed combine with two atoms of bromine and form dibromides. The dibromides on treatment with alkaline reagents easily losse hydrogen bromide and form monobromo acids. The structure of these monobromides was established by oxidation with ozone.

3. The monobromides are easily decomposed by aqueous and alcoholic potassium hydroxide. Benzaldehyde is formed. In the case of one of the monobromides about $25 \%$ of dibenzal-acetone is also produced.

4. Unsaturated keto-phosphonic acids are formed by the action of phosphorus trichloride and phosphenyl chloride on cinnamylidene-acetophenone in suitable solvents. The combination takes place in the 1,4 position as shown by oxidation with ozone.

Cambridge 38, Massachusetts.

\section{THE ACTION OF HYDROGEN PHOSPHIDE ON FORMALDEHYDE.}

\section{BY ALFRED HOFFMAN.}

Received April 18, 1921.

The condensation of hydrogen phosphide with aldehydes was studied by Messinger and Engels. ${ }^{1}$ By passing a mixture of hydrogen phosphide and dry hydrogen chloride into ethereal solutions of the aldehydes they obtained compounds of the composition (R.CHO) ${ }_{4} \mathrm{PH}_{4} \mathrm{Cl}$. Treated with potassium hydroxide these gave products assumed by the authors to be mixtures of the free phosphine and its hydrate. Similar compounds have been prepared by Girard, ${ }^{2}$ by the action of phosphonium iodide on aldehydes. Formaldehyde was not investigated by either of these authors.

1 Messinger and Engels, Ber., 21, 325 (1888).

2 Girard, Ann. chim., [6] 2, 2 (1884). 
In the experiments here described, it was found that hydrogen phosphide is readily absorbed when passed into a warm, aqueous solution of formaldehyde acidified with hydrochloric acid. On evaporation the solution gives a crystalline salt, which has the properties of a tetrahydroxymethylene-phosphonium chloride, $\left(\mathrm{HOCH}_{2}\right)_{4} \mathrm{PCl}$.

This substance is quite stable; its aqueous solution may be boiled without decomposition and it is unaffected by dil. acids. It reduces silver nitrate solution in the cold and is easily oxidized by conc. nitric acid. It is extremely sensitive toward alkalies and even neutral carbonates. With caustic soda solution, even in the cold, a vigorous evolution of hydrogen takes place. When the latter is completed by heating, it is found that exactly four atoms of hydrogen are split off. When this experiment was performed in an open tube, a slight odor of methyl alcohol was detected. If the solution is then acidified with hydrochloric acid and distilled to dryness, half a molecule of formic acid comes over. The residue of the molecule containing the phosphorus is more easily isolated when the decomposition is carried out with barium hydroxide. After removing the barium and evaporating, a thick colorless sirup remains which does not crystallize. According to the yield and to the percentage of phosphorus, the compound seerris to have the empirical formula $\mathrm{C}_{3} \mathrm{H}_{8} \mathrm{O}_{5} \mathrm{P}$, perhaps constituted $\left(\mathrm{HOCH}_{2}\right)_{3} \mathrm{PO}_{2}$. As the course of the reaction and the constitution of the compound need further clearing up, the formula is given with due reserve. The reaction may be as follows, $\left(\mathrm{HOCH}_{2}\right)_{4} \mathrm{PCl}+\mathrm{NaOH}+\mathrm{H}_{2} \mathrm{O}=\left(\mathrm{HOCH}_{2}\right)_{3} \mathrm{PO}_{2}+\mathrm{NaCl}+2 \mathrm{H}_{2}+\mathrm{HCHO}$. The formaldehyde then reacts with the sodium hydroxide to give half methyl alcohol and half formic acid. The syrupy compound is rather difficult to oxidize with nitric acid. It has feeble acid properties, forming salts, with barium carbonate, for instance, which hydrolyze on evaporating the solution. By means of the Schotten-Baumann reaction the substance gives a well crystallizing tribenzoyl derivative.

With neutral carbonates, such as calcium carbonate the action is similar, but less vigorous, and there are indications of the formation of intermediate products. On adding the carbonate to the aqueous solution of the crystalline phosphonium chloride, an evolution of carbon dioxide is observed, due to the union of the chlorine with the calcium; then on heating, a slow evolution of hydrogen takes place and one molecule of formaldehyde distils. Also a disagreeable odor is noticed, perhaps the trihydroxymethylene-phosphine. It was not found possible to isolate these intermediate compounds either as such or as benzoyl derivatives. The final product in this case also was the syrupy compound.

Of special interest is the action of ammonia on the crystalline phosphonium chloride. If dil. aqueous solutions are employed, the ammonia acts like an alkali, hydrogen is evolved and the solution remains clear. 
If, however, concentrated sclutions are used, a curdy white precipitate is formed in small amount. By working under anhydrous conditions in methyl alcohol, larger yields are obtained; but the best yields, up to almost $50 \%$ of the weight of phosphonium chloride taken, are obtained in aqueous solution with aramonium chloride and a neutral carbonate or bicarbonate. As the substance contains almost twice as much phosphorus as the phosphonium ahloride, the reaction is nearly quantitative. The ammonia derivative is a curdy, somewhat stringy, white precipitate. It is very voluminous and retains the bubbles of carbon dioxide from the carbonates, so that in fairly concentrated solutions a spongy, dough-like mass is obtained. The compound is insoluble in water, dilute acids and alkalies and all the ordinary organic solvents, but on boiling with water for several days it goes into solution, giving the ammonia salt of a complex organic phosphoric acid. It is easily soluble in cold dil. formaldehyde solution, giving a clear solution, which on evaporation leaves a spongy horn-like mass, having a pronounced fishy odor, like trimethylamine. The ammonia derivative is quite stable to heat. At a temperature far above $200^{\circ}$, it suddenly swells, gives off an odor of decayed fish and burns with a flame. With concentrated nitric acid it reacts violently, often catching fire. Its composition seems to vary somewhat. The percentage composition is phosphorus, 27 to $30 \%$; nitrogen, 14.5 to $16.2 \%$. The filtrate from the preparation of the ammonia derivative contains hexamethylene-tetramine, which could be isolated by extracting the dried residue from the solution with chloroform. Its amount corresponds roughly to one molecule of formaldehyde for each molecule of the phosphonium chloride taken, but seems to vary somewhat. The ammonia derivative is not formed from the syrupy compound. Considerable further study will be necessary to determine the constitution of the substance, as, to judge from its physical properties, it must be of high molectlar weight. It may be mentioned that aniline gives a similar precipitate with the phosphonium chloride but urea does not. The work is being continued.

\section{Experimental.}

Hydrogen Phosphide.-To prepare this gas, small quantities of a mixture of two parts aluminum powder and one part red phosphorus were prepared on a piece of paper on an asbestos pad. On igniting the paper, the mixture became white-hot and there resulted a spongy mass of aluminum phosphide. ${ }^{3}$ This substance reacts with cold water to give a steady stream of hydrogen phosphide. The gas so formed is not spontaneously inflammable at room temperature, but does ignite at the temperature of the following experiment $\left(80^{\circ}\right)$, causing small explosions in the apparatus.

Tetrahydroxy-methylene-phosphonium chloride.-A mixture of $90 \mathrm{cc}$. of $40 \%$ formaldehyde solution and $40 \mathrm{cc}$. of bydroshloric acid, (sp. gr. 1.2) was introduced into a 100-ce. 3 -bulb Ladenburg flask (it should fill about half of the neck of the flask), the latter provided

${ }^{3}$ Fonzes-Diacon, Compt. rend, 130, 1314 (1900); Bodroux, Bull. sor. chim., [3] 27, $568(1902)$. 
with a stopper through which passed a gas-delivery tube reaching to the bottom. The flask was then inclined to an almost horizontal position, hydrogen phosphide was passed in to displace the air and the solution then heated to about $80^{\circ}$. At lower temperatures the reaction is correspondingly slower and at higher temperatures the vapor pressure of the solution interferes with the absorbtion. The bulbs of the flask serve to hold back the gas and make the reaction more complete. Hydrogen and some hydrogen phosphide escape from the side-neck and should be led off to a flue. Using 10 portions of each $4 \mathrm{~g}$. of aluminum and $2 \mathrm{~g}$. of phosphorus, the reaction was complete in two days. The liquid was evaporated on the steam-bath, withstirring toward the end until a white granular mass was obtained; yield, $50 \mathrm{~g}$. (calculated yield, $57 \mathrm{~g}$.). This is pure enough for preparative purposes. For analysis it was crystallized from glacial acetic acid, $1 \mathrm{~g}$. of substance to $50 \mathrm{~g}$. of acid. It crystallizes in flat needles of low melting point containing acetic acid of crystallization, which can be removed in a current of dry air at $100^{\circ}$. The pure substance melts at $151^{\circ}$, is very deliquescent, easily soluble in methyl alcohol, slightly in hot chloroform and insoluble in ether. It reacts with acetyl chloride and acetic anhydride to give oily products.

Analysis. Subs., 0.198: $\mathrm{AgCl}, 0$ 150. Subs., 0.217: $\mathrm{Mg}_{2} \mathrm{P}_{2} \mathrm{O}_{i}, 0.127$. Calc. for $\mathrm{C}_{4} \mathrm{H}_{12} \mathrm{O}_{4} \mathrm{PCl}: \mathrm{Cl}, 18.6 ; \mathrm{P}, 16.2$. Found: $\mathrm{Cl}, 18.68: \mathrm{P}, 16.1$.

Action of Sodium Hydroxide.-Analysis. Subs., $0.175: 44.7$ cc. moist hydrogen at $12^{\circ}, 750 \mathrm{~mm}$. $=41.6 \mathrm{cc}$. dry hydrogen at $0^{\circ}, 760 \mathrm{~mm}$. Calc. for two molecules of hydrogen: $41.1 \mathrm{cc}$.

After acidifying with hydrochloric acid and distilling to dryness, the distillate was neutralized and treated with mercuric chloride solution."

Analysis. Subs., $0.976: \mathrm{Hg}_{2} \mathrm{Cl}_{2}, 1.315=0.128 \mathrm{~g}$. formic acid. Calc. for 0.5 molecule formic acid: $0.118 \mathrm{~g}$.

Action of Barium Hydroxide.-A nalysis. Subs., 0.691, treated with barium hydroxide solution and the barium removed quantitatively, gave $0.556 \mathrm{~g}$. of syrup dried to constant weight. Calc. for $\mathrm{C}_{3} \mathrm{H}_{9} \mathrm{O}_{5} \mathrm{P}: 0.567 \mathrm{~g}$. $0.526 \mathrm{~g}$. of sirup gave $0.364 \mathrm{~g} . \mathrm{Mg}_{2} \mathrm{P}_{2} \mathrm{O}_{7}$. Calc. for $\mathrm{C}_{3} \mathrm{H}_{9} \mathrm{O}_{5} \mathrm{P}: \mathrm{P}, 19.8$. Found: 19.3 .

Action of Calcium Carbonate.-.Anaiysis. Subs.1.008 in aqueous solution distilled with calcium carbonate and the distillate treated with a solution of mercuric chloride, sodium hydroxide and sodium sulfite ${ }^{5}$ gave $1.116 \mathrm{~g}$. Hg. Calc. for one molecule formaldehyde: 0.159 . Found: 0.167 .

Preparation of the Tribenzoyl Derivative of the Syrupy Compound.-The crystalline phosphonium chloride was boiled with a large excess of sodium hydroxide solution, (1-10), until no more hydrogen was given off, and the solution was cooled and shaken with a slight excess of benzoyl chloride until the oil solidified. Fine needles were obtained on crystallization from methyl alcohol, m. p. $111^{\circ}$, easily soluble in hot methyl alcoinol but insoluble in water.

Analysis. Subs, $0.402 \mathrm{~g}: \mathrm{Mg}_{2} \mathrm{P}_{2} \mathrm{O}_{7}, 0.100$. Calc. for $\left(\mathrm{C}_{6} \mathrm{H}_{5} \mathrm{COOCH}_{2}\right)_{3} \mathrm{PO}_{2} ; \mathrm{P}, 6.62$. Found: 6.94 .

\section{Summary.}

The action of hydrogen phosphide on a warm, aqueous solution of formaldehyde, acidified with hydrochloric acid, was studied and the reaction product tetrahydroxy-methylene-phosphonium chloride isolated and its properties studied. By the action of alkalies or carbonates on the

4"Beilstein," 4th ed. Vol. II, p. 13.

" "Beilstein," 4th ed. Vol. I, p. 570. 
latter, a compound, $\mathrm{C}_{3} \mathrm{H}_{9} \mathrm{O}_{5} \mathrm{P}$, was formed and its tribenzoyl derivative prepared. The action of ammonium chloride and calcium carbonate on tetrahydroxy-methylene-phosphonium chloride was studied and an insoluble curdy precipitate containing about $30 \%$ of phosphorus and $15 \%$ of nitrogen obtained.

KEW Gardens, N. Y.

[CONTRIBUTion From THE DEPARTMENT OF Pharmacology, UNIVERSity OF MinNeSOTA.]

\title{
SOME DERIVATIVES OF SALIGENIN. ${ }^{1}$
}

\author{
BY MERRIIL C. HART AND ARTHUR D. HIRSChFILDER. \\ Received April 20, 1921.
}

Since Hirschfelder, Lundholm and Norrgaard ${ }^{2}$ have shown that saligenin (o-hydroxy-benzyl alcohol) possesses valuable properties as a local anesthetic it was thought that an investigation of some of the derivatives of saligenin might also prove valuable. In this study it is desired to vary the saligenin molecule in several different ways and to study pharmacologically the different properties of the derivatives.

The saligenin molecule was first altered by varying the phenolic hydroxyl and simple ethers (Formula I) were synthesized. In this case ethers where $\mathrm{R}$ was both aliphatic and aromatic were prepared. The ethyl<smiles>[R]OC1CCCCC1O</smiles>

(I).<smiles>[R]C(=O)OC1CCCCC1</smiles>

(II).<smiles>CCCCCCC(=O)OC1CCCCC1</smiles>

(III)

propyl, $n$-butyl, iso-amyl, and the benzyl ethers of saligenin were made.

Other variations of the molecule were then prepared by making the esters of saligenin (Formula II) upon the phenolic hydroxyl. Representatives of this class of compounds were made by preparing the mono-acetate and the monobenzoate of saligenin. The mono-acetate was particularly desired because of its relation to acetyl salicylic acid (aspirin).

Also a derivative of saligenin, the dibenzoate, was prepared as a representative of the case where both the groups in the saligenin molecule were masked (Formula III).

The saligenin molecule was next modified by varying the nucleus. As the simplest and easiest way of doing this seemed through the introduction

1 This work was done with the aid of funds granted by the United States Interdepartmental Board, for the investigation of the antiseptic and chemotherapeutic action of phenolic alcohols and their derivatives upon the gonococcus and the spirochaete.

${ }^{2}$ Hirschfelder, L,undholm and Norrgaard, Science, N. S., 51, 21 (1920); J. Pharmacol. 15, 263 (1920). 